\title{
Rapid Revelation of Radiocarbon Records with Laser Ablation Accelerator Mass Spectrometry
}

\author{
Caroline Münsterer ${ }^{\text {sab }}$, Lukas Wackerb, Bodo Hattendorfa, Marcus Christ ${ }^{\mathrm{b}}$, Joachim Koch ${ }^{\mathrm{a}}$, \\ Rolf Dietiker ${ }^{a}$, Hans-Arno Synal ${ }^{b}$, and Detlef Günther ${ }^{\star a}$
}

§SCS-Metrohm Foundation Award for best oral presentation

\begin{abstract}
By focusing high-intensity laser pulses on carbonate samples carbon dioxide is generated and can be directly introduced into the gas ion source (GIS) of an Accelerator Mass Spectrometer (AMS). This new technique allows rapid radiocarbon analyses at high spatial resolution. The design of the deignated laser ablation cell as well as first results on a stalagmite sample are presented.
\end{abstract}

Keywords: Accelerator mass spectrometry $(\mathrm{AMS}) \cdot$ Carbonates $\cdot$ Laser ablation $\cdot$ Radiocarbon

Radiocarbon $\left({ }^{14} \mathrm{C}\right)$ is an important isotope for the investigation of carbonates such as stalagmites or corals. Applications range from the indirect dating of young stalagmites, by using the excess ${ }^{14} \mathrm{C}$ generated during nuclear weapons testing ('bomb peak') as a time marker,[1] to the tracing of broad redistributions of water masses via the ${ }^{14} \mathrm{C}$-signal recorded in deepwater corals. ${ }^{[2]}$ This requires acquisition of ${ }^{14} \mathrm{C}$ data at high spatial resolution, implying that numerous samples need to be taken and processed. Conventionally, ${ }^{14} \mathrm{C}$ detection with accelerator mass spectrom-

\footnotetext{
${ }^{\star}$ Correspondence: Prof. Dr. D. Günther ${ }^{a}$

Tel.: +4144633 3475

E-Mail: guenther@inorg.chem.ethz.ch

${ }^{\mathrm{a} E T H}$ Zurich

Department of Chemistry and Applied Biosciences

Laboratory of Inorganic Chemistry

$\mathrm{HCl} \mathrm{G} 113$

Vladimir-Prelog-Weg 1

$\mathrm{CH}-8093$ Zurich

'ETH Zurich

Laboratory of Ion Beam Physics

Schafmattstr. 20, $\mathrm{CH}-8093$ Zurich
}

etry (AMS) makes mechanical drilling of the sample material necessary, limiting the achievable spatial resolution. Furthermore, laborious chemical processing is needed in order to extract the carbon from the sample material and convert it either into graphite or $\mathrm{CO}_{2}$. By using laser ablation (LA) as a sampling method in combination with gas ion source (GIS)-AMS, ${ }^{[3]}{ }^{14} \mathrm{C}$ analysis with high spatial resolution can be performed much more rapidly. Here, $\mathrm{CO}_{2}$ is generated by material decomposition upon exposure of a focused high intensity laser beam. The so-formed gas can directly be introduced into a GIS-AMS. An overview of the setup is depicted in Fig. 1.

For the direct coupling of LA with AMS a LA unit was developed consisting of an ablation cell with an effective volume of approximately $0.6 \mathrm{~mL}$. The dedicated ablation cell design (Fig. 2) provides short washout times with minimal particle deposition on the cell window and sample surface. Consequently, short measurement times can be achieved and cross-contamination is reduced. At the same time large samples $\left(150 \times 25 \times 15 \mathrm{~mm}^{3}\right)$ can be hosted by the cell and moved by a computer controlled positioning system at high spatial resolution relative to the laser beam. An $\operatorname{ArF}-E x c i m e r$ Laser $(\lambda=193 \mathrm{~nm})$ is guided to the sample surface, allowing for ablation at a scale of less than $100 \mu \mathrm{m}$.

A preliminary characterization of the setup has been carried out and measurements of different standard materials and natural samples were performed. In these studies, the reference value for a pressed carbonate reference standard (IAEA C2) with a ${ }^{14} \mathrm{C}$-activity ratio of $41.14 \pm 0.03$ pMC was measured and a value of 41.9

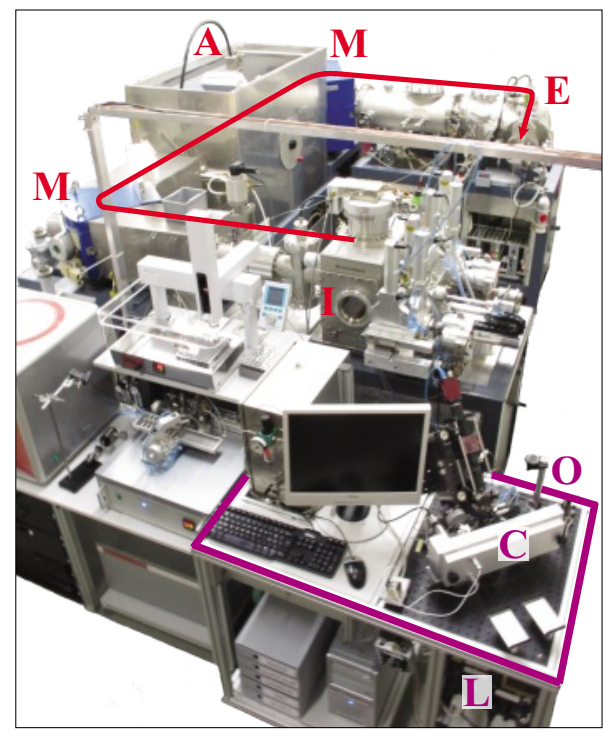

Fig. 1. Overview of the LA unit (purple frame) and the AMS (red frame). L: Laser Source, C: Ablation Cell and positioning system, O: Optical setup, I: Ion source, M: Magnet, A: Accelerator, E: Electrostatic analyzer.

\pm 1.6 pMC was derived. Furthermore, a stalagmite sample with a conventionally derived ${ }^{14} \mathrm{C}$ profile that shows the radiocarbon signature of the bomb peak ${ }^{[4]}$ was analyzed. The black triangles in Fig. 3 represent data from micro drilling and subsequent graphitization whereas the red dots depict the results for LA-GIS-AMS. With the LA-setup the conventionally derived ${ }^{14} \mathrm{C}$ profile of the stalagmite could be accurately reproduced. This method allows an analysis of such radiocarbon profiles within only $\sim 2 \mathrm{~h}$ compared to $12 \mathrm{~h}$ required with the conventional method for the same amount of samples. The spatial resolution 


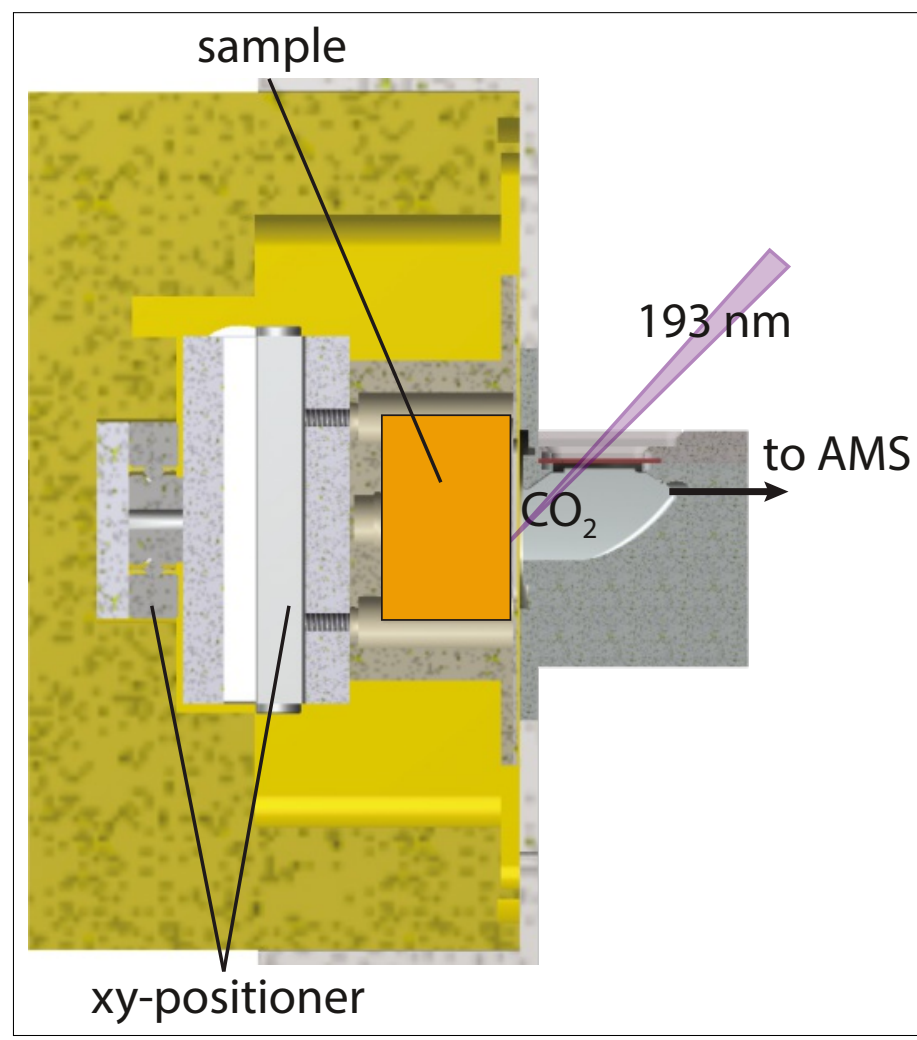

Fig. 2. Cross section of the laser ablation cell (located inside of ' $C$ ' in Fig. 1).

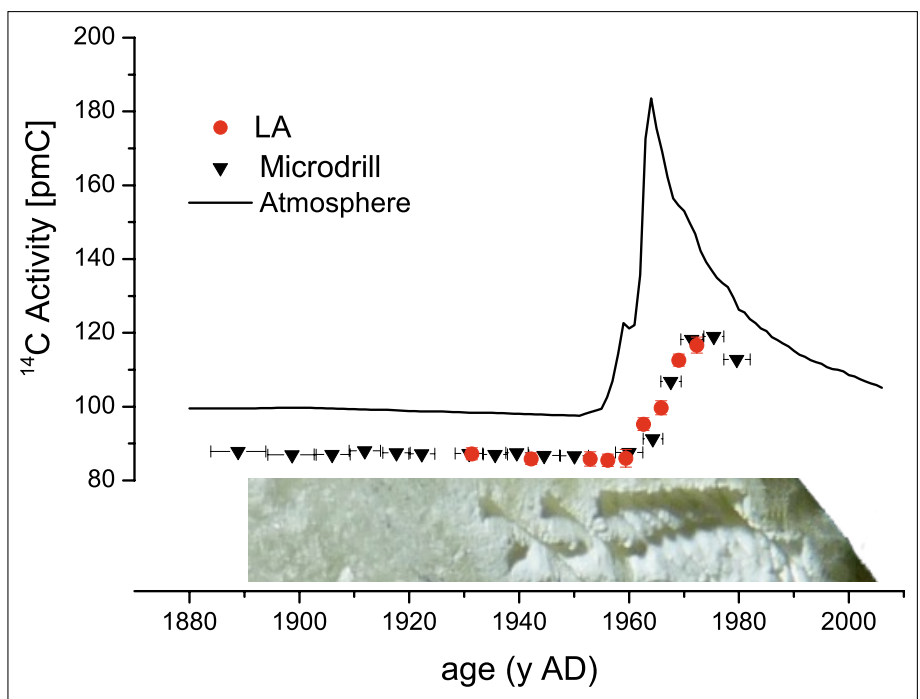

Fig. 3. Comparison of conventionally processed radiocarbon data (black triangles) with LA sampling (red dots). in this experiment was not at its limit and can be improved by a factor of two or three.

Future work will comprise a modification of the LA-setup in order to increase the signal intensity, which will allow for a higher precision and shorter measurement times. These first investigations using the described in-house developed LA-setup coupled to AMS indicate that this new sampling technique will be very suited for rapid ${ }^{14} \mathrm{C}$ analysis of carbonate records at high spatial resolution.

Received: January 20, 2014

[1] E. Hodge, J. McDonald, M. Fischer, D. Redwood, Q. Hua, V. Levchenko, R. Drysdale, C. Waring, D. Fink, Radiocarbon 2011, 53, 345.

[2] N. Frank, M. Paterne, L. Ayliffe, T. van Weering, J. P. Henriet, D. Blamart, Earth Plan. Sci. Let. 2004, 219, 207.

[3] M. Ruff, L. Wacker, H. W. Gaggeler, M. Suter, H. A. Synal, Radiocarbon 2007, 49, 307.

[4] J. Fohlmeister, B. Kromer, A. Mangini, Radiocarbon 2011, 53, 99. 